\title{
Study on dietary pattern and physical activity before diagnosis of cancer in cancer patients of a teaching hospital of Jharkhand: A pilot study
}

\author{
Dewesh Kumar ${ }^{1, *}$, Santosh Kumar Soren ${ }^{2}$, Erum Yasmin ${ }^{3}$, Vivek Kashyap ${ }^{4}$, Rishabh Singh ${ }^{5}$ \\ ${ }^{\mathbf{1}}$ Assistant professor, ${ }^{\mathbf{2}, 3}$ Junior Resident, ${ }^{4}$ Professor and Head, ${ }^{5}$ MBBS Student, Dept. of PSM, Rajendra Institute of \\ Medical Sciences, Ranchi, India
}

*Corresponding Author:

Email: dr.dewesh@gmail.com

\begin{abstract}
Introduction: Cancer is among the leading causes of death worldwide. It poses a major threat to public health worldwide, and incidence has increased in most countries since 1990. The study aims to find any association between dietary factors and physical activity with the risk of cancer.

Material and Methods: The study was conducted at Oncology, Surgery, Gynecology and Medicine department of RIMS, Ranchi. The study was conducted from Sept.2017- Nov.2017 (three months). It was a case-control (analytical) hospital based study. The sampling technique used was simple random sampling. A total of 30 cases and 30 controls was studied considering the limitation of time and resources. Data recorded in pretested and predesigned Performa after taking their consent. Data were compiled and analyzed using proper statistical methods.

Results: In our study, majority of the cases were female, mostly were of age group more than 40 yrs. Most of them were Hindu, non-tribal \& mostly illiterate and self-employed. Most of the cases were non-vegetarian and consumed low amount of cereals and vegetables. We found that cancer patients $(66.7 \%)$ consumed less than $250 \mathrm{gms}$ of vegetables per day $(\mathrm{p}<0.05)$ and also cereals $(250 \mathrm{gms})(\mathrm{p}<0.05)$. Cases had higher amount of alcohol consumption.

Conclusion: It may be concluded from the study that diet pattern and physical activity do have a role in Cancer etiology but needs a larger sample size to establish it.
\end{abstract}

Keywords: Cancer, Dietary pattern, Physical activity.

\section{Introduction}

Cancer is among the leading causes of death worldwide. It poses a major threat to public health worldwide, and incidence has increased in most countries since 1990 . The trend is a particular threat to developing countries with health systems that are illequipped to deal with complex and expensive cancer treatment. Cancer caused over 8 million deaths in 2012 and has moved from the third leading cause of death to the second leading cause behind cardiovascular diseases in 2013. ${ }^{1}$ Globally, during 2012, the most common cancer diagnosed were those of the lung (1.8 million), breast(1.7 million), and colorectal cancer(1.4 million). The most common causes of cancer deaths were cancer of lung (1.6 million, liver (0.8 million) and stomach (0.7 million)

In 2012, the worldwide burden of cancer rose to an estimated 14 million new cases per year with an estimated 8.2 million cancer deaths annually. Over the next two decades cancer incidence is predicted to rise to 14 million new cases annually while cancer deaths may rise to 13 million per year. ${ }^{2}$ In India during the same period 10.15 lac new cancer cases occurred and about 6.83 lac people died due to cancer. ${ }^{2}$ The five most frequent cancers in man are cancer lung, lip and oral cavity, stomach, colorectal and other pharynx, and in women cancer breast, cervix, uterus, colorectal, ovary, lip and oral cavity. As per data provided by ICMR, the estimated incidence of cancer cases in Jharkhand was 28135 in 2011, 29067 in 2012, 30026 in 2013 and 31012 in 2014.The estimated cancer mortality in Jharkhand was 12380 in 2011, 12790 in 2012, 13211 in 2013, and 13645 in 2014.

Substantial progress has been made in recent years with regard to prevention and treatment options for certain cancers. However, despite this progress, cancer burden is increasing owing to a growing and aging global population as well as risk factors like smoking, obesity, and dietary patterns. Cancer screening is the best approach for early detection and prompt treatment of early cancer and precancerous condition provide the protection against cancer for the individual and the community.

The proposals that cancer might be preventable, and that food, nutrition, physical activity, and body composition might affect the risk of cancer, have been made in several studies all over the world. Throughout recorded history, wise choices of food and drink, and of habitual behaviour, have been recommended to protect against cancer, as well as other diseases, and to improve well-being. It has been estimated that $30-40 \%$ of all cancers can be prevented by lifestyle and dietary measures. ${ }^{2}$ Cancer has become the second leading cause of death worldwide, behind cardiovascular disease. A sharp increase in incidence and mortality has been observed in India. However facilities for screening and proper management of cancer patients are grossly limited. More than two-thirds of the cancer patients are already in an advanced or incurable stage at the time of diagnosis. The treatment of also poses a huge 
economical burden on the individual and also on the economy of a developing country like India. So, there is a need to approach towards control of cancer through primary and secondary prevention. Since dietary factors and physical exercise have been implicated as risk factors for several cancers, a study to analyze association between these factors and cancer causation may be helpful in decreasing incidence and mortality due to cancer. Viewed in this context the present study was undertaken with the following aims and objectives:

1. To study the socio-demographic profile in admitted cancer patients.

2. To find the association between dietary factors, physical activity with the risk of cancer amongst the study groups.

\section{Material and Methods}

This case-control (analytical) study was conducted at Oncology, Surgery, Gynecology and Medicine department of RIMS, Ranchi. The institute is a tertiary care center catering almost entire state and bordering districts of neighboring states. The study was conducted from Sept.2017-Nov.2017 (three months). It was a casecontrol (analytical) hospital based study. The sampling technique used to select cases and controls was simple random sampling. A total of 30 cases and 30 controls were studied following the principle of cases: controls to be 1:1 considering the limitation of time and resources.

\section{Study population}

Case: Patients diagnosed with cancer attending the above mentioned departments of RIMS

Control: Relatives or attendants of the patient not having cancer or not suffered from cancer in the past were recruited as control. But it was not necessarily the attendant of the recruited cases only. Controls were also randomly selected.
Inclusion criteria: Any patient of any age suffering from any Cancer and giving his or consent to be the participant of the study.

Exclusion criteria: All patients who were terminally ill, on ventilator support, patients with congenital tumours, uncooperative patients and patients who are not willing to participate.

Study tool: A pre tested semi structured questionnaire was used as a study tool containing different sections viz. socio-demographic, past history, diet, physical activity and miscellaneous.

\section{Data analysis}

Data collected was entered in template made in MSExcel sheet. Data thus collected were compiled and analyzed using proportions and percentages for qualitative data and for quantitative data mean, median, mode were used. Further association was calculated using Odd's ratio (OR) considering Case-Control study. Chi-square/Fisher exact test was used as test of significance where qualitative data is expressed as $2 \times 2$ contingency table. $\mathrm{P}<0.05$ was considered as statistically significant.

\section{Results}

In this study, majority of the cases were female (60\%), mostly were of age group more than 40 yrs. Most of them were Hindu (73\%), non-tribal (63\%) \& mostly illiterate (43\%) and self-employed. Cases were equally from both rural and urban background. Since the controls were not necessarily the attendants of the recruited cases, the socio-demographic profile did not match in this study. In comparison to cases, male outnumbered the females in control group and controls were more from urban families. (Table 1)

Table 1: Sociodemographic profile

\begin{tabular}{|l|l|c|c|}
\hline & & Cases(n=30) & Control(n=30) \\
\hline \multirow{2}{*}{ Gender } & Male & $12(40 \%)$ & $19(63 \%)$ \\
\cline { 2 - 4 } & Female & $18(60 \%)$ & $11(37 \%)$ \\
\hline \multirow{3}{*}{ Ethnicity } & Tribal & $11(37 \%)$ & $8(27 \%)$ \\
\cline { 2 - 4 } & Non-tribal & $19(63 \%)$ & $22(73 \%)$ \\
\hline \multirow{4}{*}{ Edigion } & Hindu & $22(73 \%)$ & $21(70 \%)$ \\
\cline { 2 - 4 } & Muslim & $7(23 \%)$ & $7(23 \%)$ \\
\cline { 2 - 4 } & Christian & $1(4 \%)$ & $2(7 \%)$ \\
\hline & Illiterate & $13(43 \%)$ & $5(17 \%)$ \\
\cline { 2 - 4 } & Primary School & $9(30 \%)$ & $5(17 \%)$ \\
\cline { 2 - 4 } & High School & $4(13 \%)$ & $3(10 \%)$ \\
\cline { 2 - 4 } & Intermediate & $1(4 \%)$ & $8(26 \%)$ \\
\cline { 2 - 4 } & $\begin{array}{l}\text { Graduate or } \\
\text { above }\end{array}$ & $3(10 \%)$ & $9(30 \%)$ \\
\hline $\begin{array}{l}\text { Place of } \\
\text { Residence }\end{array}$ & Rural & $15(50 \%)$ & $10(33 \%)$ \\
\cline { 2 - 4 } & Urban & $15(50 \%)$ & $20(67 \%)$ \\
\hline
\end{tabular}


Most of the cases were non-vegetarian and consumed low amount of cereals and vegetables. (Table $2 \& 3$ ). The odds of occurring cancer in persons having non-vegetarian diet was four times more than the persons having vegetarian diet. It was found that cancer patients $(66.7 \%)$ consumed less than $250 \mathrm{gms}$ of vegetables per day and less cereals also $(\mathrm{p}<0.05)$. It was also noted that people consuming less calories are more at risk to develop cancer in comparison to persons having adequate calories. Even consuming less vegetables was a risk factor in the development of cancer. Consumption of fruits was very less and in both the groups, it was less than a month so drawing an inference out of it was not convincing.

Table 2: Dietary Pattern

\begin{tabular}{|l|l|c|c|c|c|}
\hline & & Cases & Control & P value & OR \\
\hline \multirow{2}{*}{ Type of Diet } & Non Vegetarian & $28(93 \%)$ & $23(77 \%)$ & 0.071 & 4.26 \\
\cline { 2 - 5 } & Vegetarian & $2(7 \%)$ & $7(23 \%)$ & & \\
\hline
\end{tabular}

Table 3: Cereals and vegetables consumption

\begin{tabular}{|l|c|c|c|c|c|}
\hline \multicolumn{1}{|c|}{ Dietary habit } & & Cases & Control & P value & OR \\
\hline $\begin{array}{l}\text { Amount of cereals } \\
\text { consumed in a day }\end{array}$ & Less than $250 \mathrm{~g}$ & $23(77 \%)$ & $15(50 \%)$ & 0.032 & 3.29 \\
\cline { 2 - 4 } $\begin{array}{l}\text { Amount of } \\
\begin{array}{l}\text { vegetables } \\
\text { consumed in a day }\end{array}\end{array}$ & Mess than $250 \mathrm{~g}$ & $7(23 \%)$ & $15(50 \%)$ & & \\
\cline { 2 - 4 } & More than $250 \mathrm{~g}$ & $20(67 \%)$ & $11(34 \%)$ & 0.020 & 3.45 \\
\hline
\end{tabular}

Cases had higher amount of alcohol consumption but the difference in exposure risk was not statistically significant. Since smoking is not that prevalent in Jharkhand so nothing conclusive on this data can be said but the persons with more than 20 years smoking history are 12 times at more risk than the smoking history of less than 20 years. Cases were more chronic smokers with duration more than 20 years and smoked more than 3 cigarettes per day in comparison to controls. In this part of country smokeless tobacco is rampant and cases are more exposed to this pouch menace. (Table 4 \& 5) Majority of the cases were not involved in physical activities. (Table 6)

Table 4: Non vegetarian food consumption

\begin{tabular}{|l|l|c|c|c|c|}
\hline & & Cases(n=28) & Control(n=23) & P value & OR \\
\hline \multirow{2}{*}{$\begin{array}{l}\text { Frequency of non } \\
\text { veg consumption } \\
(\mathrm{n}=53)\end{array}$} & $\begin{array}{l}\text { More than 2 } \\
\text { days/week }\end{array}$ & $18(64 \%)$ & $14(61 \%)$ & 0.802 & 1.16 \\
\cline { 2 - 4 } & $\begin{array}{l}\text { Less than 2 } \\
\text { days/week }\end{array}$ & $10(36 \%)$ & $9(40 \%)$ & 0.487 & 0.60 \\
\cline { 2 - 4 } $\begin{array}{l}\text { Amount of non } \\
\text { veg consumed } \\
\text { (per week) }\end{array}$ & More than 500g & $4(14 \%)$ & $5(22 \%)$ & $18(78 \%)$ & \\
\cline { 2 - 4 }
\end{tabular}

Table 5: Drinking Pattern and Smoking habits

\begin{tabular}{|c|c|c|c|c|c|}
\hline & & $\begin{array}{l}\text { Cases } \\
(\mathbf{n}=30)\end{array}$ & $\begin{array}{c}\text { Control } \\
(\mathbf{n}=30)\end{array}$ & P value & OR \\
\hline \multirow{2}{*}{ Alcohol Consumption } & Yes & $7(23 \%)$ & $6(20 \%)$ & \multirow{2}{*}{0.75} & \multirow[t]{2}{*}{0.82} \\
\hline & No & $23(77 \%)$ & $24(80 \%)$ & & \\
\hline \multirow{2}{*}{ Smoking } & Yes & $5(17 \%)$ & $4(13 \%)$ & \multirow[t]{2}{*}{0.71} & \multirow[t]{2}{*}{1.30} \\
\hline & No & $25(83 \%)$ & $26(87 \%)$ & & \\
\hline \multirow{2}{*}{ Duration of smoking } & $\begin{array}{l}\text { More than } 20 \text { years } \\
(n=5)\end{array}$ & $4(80 \%)$ & $1(25 \%)$ & \multirow[t]{2}{*}{0.099} & \multirow[t]{2}{*}{12} \\
\hline & $\begin{array}{l}\text { Less than } 20 \text { years } \\
(n=4)\end{array}$ & $1(20 \%)$ & $3(75 \%)$ & & \\
\hline \multirow{2}{*}{$\begin{array}{l}\text { Smokeless/chewable } \\
\text { tobacco consumption }\end{array}$} & Yes & $9(30 \%)$ & $5(17 \%)$ & \multirow[t]{2}{*}{0.222} & \multirow[t]{2}{*}{2.14} \\
\hline & No & $21(70 \%)$ & $25(83 \%)$ & & \\
\hline \multirow{2}{*}{$\begin{array}{l}\text { Average no. of } \\
\text { sachets per day }\end{array}$} & More than $3(n=5)$ & $4(44 \%)$ & $1(20 \%)$ & \multirow[t]{2}{*}{0.36} & \multirow[t]{2}{*}{2.14} \\
\hline & Less than $3(n=9)$ & $5(56 \%)$ & $4(80 \%)$ & & \\
\hline
\end{tabular}


Table 6: Physical Activity

\begin{tabular}{|l|l|c|c|c|c|}
\hline & & Cases & Control & P value & OR \\
\hline \multirow{2}{*}{$\begin{array}{l}\text { Level of physical } \\
\text { activity }\end{array}$} & Sedentary/Mild & $13(43 \%)$ & $11(37 \%)$ & 0.36 & 1.32 \\
\cline { 2 - 4 } \multirow{2}{*}{$\begin{array}{l}\text { Hours of Moderate } \\
\text { Physical activity }\end{array}$} & Moderate/ Intense & $17(57 \%)$ & $19(63 \%)$ & & \\
\cline { 2 - 4 } & $\begin{array}{l}\text { Mess than 2 hr per day } \\
\text { day }\end{array}$ & $22(73 \%)$ & $20(67 \%)$ & 0.57 & 1.37 \\
\hline
\end{tabular}

\section{Discussion}

Our study was conducted in the department of Oncology, Surgery, Medicine, Gynaecology, RIMS, Ranchi involving a total of 60 participants of which 30 were cases and 30 controls. The results obtained are compared with studies previously conducted. According to our study, $40 \%$ of cases were male and $60 \%$ were female. Majority of them being illiterate belonging to non-tribal Hindu community.

In our study we found that cancer patients (66.7\%) consumed less than $250 \mathrm{gms}$ of vegetables per day. In a study conducted by Block G, et al. it was also inferred than overall frequency of vegetable and fruit consumption was associated with lower risks. ${ }^{3}$ The "Food, nutrition and the prevention of cancer: a global perspective 1997" conducted by WCRF/ AICR stated that $30-40 \%$ of all cancers can be prevented by appropriate diets and maintenance of appropriate body weight. ${ }^{4}$ In the "Overweight, obesity, and mortality from cancer in a prospectively studied cohort of U.S. adults", the authors estimated that over 90000 cancer deaths every year could be prevented if the adult population all maintained a normal weight $(\mathrm{BMI}<25.0){ }^{5}$

In our study amount of cereals consumed in a day more than $250 \mathrm{gm}$ in cases was $23 \%$. In a case control study "Glycemic index, glycemic load and risk of gastric cancer" conducted in Italy between 1985 and 1997, an association has been found in upper aerodigestive, endometrial ovarian colon or colorectal cancer. ${ }^{6-10}$

In our study we found that cancer patients (64.7\%) ate non-vegetarian diet more than twice a week. A similar result have been found by studies done in Canada and China which suggests that 'meat intake prior to cancer diagnosis is associated with higher risk of tumour recurrence, metastasis and death'. High intake of red meat, and particularly of processed meat, was associated with a moderate but significant increase in colorectal cancer risk. ${ }^{11}$

In our study we found that cancer patients (57.1\%) had more than 5 standard drinks per week. A study done by G. Poschl and H. K. Seitz also suggests that chronic alcohol consumption is a major risk factor for upper aero digestive tract cancer. Alcohol consumption in France appears to cause almost $8 \%$ of new cancer cases, with light and moderate drinking contributing appreciably to this burden. ${ }^{12}$

Cases had chronic smoking for $20 \mathrm{yrs}$ and $75 \%$ of which smoked more than 3 cigarettes per day. Similar results have been found in a research published done by Sara Gandini, Simona Lodice which suggests that smoking is an established risk factor in many forms of cancer. Smoking is by far the most important cause of cancer that can be modified at the individual level. Cancer incidence and mortality rates in Korea are the highest among all Asian countries, and smoking prevalence in Korean men is one of the highest in developed countries. ${ }^{13}$

In a study done by Richard Muwonge and Rengaswamy Sankaranarayan it was found that tobacco chewing was the strongest risk factor associated with oral cancer. In our study we also found that $44.4 \%$ cases chewed more than 3 packets per day. Although tobacco deaths rarely make headlines, tobacco kills one person every six seconds. Tobacco kills a third to half of all people who use it, on average 15 years prematurely. ${ }^{14}$

In our study we found that majority of the cases were lacked in physical activities. A study done by Friedenreich et al also suggest that there is strong epidemiologic evidence for reduced risk of some cancers with increasing physical activity. ${ }^{15}$ Investigations of the independent associations of physical inactivity with cancer endpoints have been mounting in the epidemiological literature, in part due to the high prevalence of physical inactivity among cancer patients and to evidence that inactivity associates with carcinogenesis via pathways independent of obesity. ${ }^{16}$

\section{Conclusion}

Majority of the cases were female, mostly were of age group more than $40 \mathrm{yrs}$. Most of them were Hindu, non tribal \& mostly illiterate and self employed. Most of the cases were non-vegetarian and consumed low amount of cereals and vegetables. Drinker cases had higher amount of alcohol consumption. Cases were chronic smokers with duration more than 20 years and smoked more than 3 cigarettes per day. Majority of the cases were lacked in physical activities and were not involved in spiritual activities.

\section{Acknowledgements}

The authors thank all the participants and staff of different ward unit for their support. We are grateful for the expert help of faculties and also acknowledge critical manuscripts review by multiple colleagues.

Funding: No funding sources.

Conflict of interest: None declared. 


\section{References}

1. Lozano R, Naghavi M, Foremark K. et al: Global and regional mortality from 235 causes of death for 20 age groups in 1990 and 2010: a systematic analysis for the Global Burden of Disease Study 2010.[PubMed]

2. 2.Park K. Park's Textbook of Preventive and Social Medicine. $24^{\text {th }}$ edition. Bhanot publishers, Jabalpur, India; 2017:400-01.

3. Block G, Patterson B, Subar A. Fruit, vegetables, and cancer prevention: a review of the epidemiological evidence. Nutr Cancer 1992;18:1-29. [PubMed]

4. WCRF/AICR. Food, nutrition and the prevention of cancer: a global perspective: World Cancer Research Fund / American Institute for Cancer Research. 1997. [PubMed]

5. Calle EE, Rodriguez C, Walker-Thurmond K, Thun MJ. Overweight, obesity, and mortality from cancer in a prospectively studied cohort of U.S. adults. $N$ Engl $J$ Med 2003;348:1625-38. [PubMed]

6. Augustin LS, Gallus S, Franceschi S, Negri E, Jenkins DJ, Kendall CW, Dal Maso L, Talamini R, La Vecchia C. Glycemic index and load and risk of upper aero-digestive tract neoplasms (Italy) Cancer Causes Control. 2003;14:657-62.[PubMed]

7. Augustin LS, Gallus S, Bosetti C, Levi F, Negri E, Franceschi S, Dal Maso L, Jenkins DJ, Kendall CW, La Vecchia C. Glycemic index and glycemic load in endometrial cancer. Int J Cancer 2003;105:40407. [PubMed]

8. Augustin LS, Polesel J, Bosetti C, Kendall CW, La Vecchia C, Parpinel M, Conti E, Montella M, Franceschi S, Jenkins DJ, Dal Maso L. Dietary glycemic index, glycemic load and ovarian cancer risk: a case-control study in Italy. Ann Oncol 2003;14:78-84. [PubMed]]

9. Franceschi S, Dal Maso L, Augustin L, Negri E, Parpinel M, Boyle P, Jenkins DJ, La Vecchia C. Dietary glycemic load and colorectal cancer risk. Ann Oncol 2001;12:17378.[PubMed]
10. Slattery ML, Boucher KM, Caan BJ, Potter JD, Ma KN. Eating patterns and risk of colon cancer. Am J Epidemiol1998;148:4-16. [PubMed]

11. Norat T, Lukanova A, Ferrari P, Riboli E. Meat consumption and colorectal cancer risk: dose-response meta-analysis of epidemiological studies. Int $J$ Cancer 2002;98:241-56. [PubMed]

12. 12.Shield KD, Micallef CM, Touvier M, Arwidson P, Bonaldi C, Bray F, SoerjomataramI. New cancer cases in France in 2015 attributable to different levels of alcohol consumption [PubMed]

13. Park S, Jee SH, Shin HR, Park EH, Shin A, Jung KW, Hwang SS, Cha ES, Yun YH, Park SK, Boniol M, Boffetta P. Attributable fraction of tobacco smoking on cancer using population-based nationwide cancerincidence and mortality data in Korea. [PubMed]

14. Mahapatra S, Kamath R, Shetty BK, Binu VS. Risk of oral cancer associated with gutka and other tobacco products: a hospital-based case-control study. [PubMed]

15. 15.Friedenreich CM, Drenstein MR. physical activity and cancer prevention: etiological evidence and biological mechanisms. J Nutr 2002;132:3456S-64S. [PubMed]

16. Cannioto R, Etter JL, LaMonte MJ, Ray AD, Joseph $\mathrm{JM}, \mathrm{Al}$ Qassim E, Eng KH, Moysich KB Lifetime physical inactivity is associated with lung cancer risk and mortality, Cancer Treat Res Commun 2018;14:37-45.

How to cite the article: Kumar D., Soren S., Yasmin E., Kashyap V., Singh B. Study on dietary pattern and physical activity before diagnosis of cancer in cancer patients of a teaching hospital of Jharkhand: A pilot study. IP Int J Med Paediatr Oncol 2018;4(3):114-118. 